\title{
Genetic Profile of Inborn Errors of Immunity Using Whole Exome Sequencing in Individuals With BCG Localized Adverse Events
}

\author{
Sandra Aparecida Moreira Gomes Monteiro \\ Universidade Federal de São Paulo \\ Renan Paulo Martin \\ Johns Hopkins University School of Medicine \\ Rafael Filippelli-Silva \\ Universidade Federal de São Paulo \\ Maryana Mara Marins \\ Universidade Federal de São Paulo \\ Caio Perez Gomes \\ Universidade Federal de São Paulo \\ Patricia Varela \\ Universidade Federal de São Paulo \\ Agatha Ribeiro Mendes \\ Universidade Federal de São Paulo \\ Priscila Nicolicht de Amorim \\ Universidade Federal de São Paulo \\ Erica Assis \\ Universidade Federal de São Paulo \\ João Bosco Pesquero \\ Universidade Federal de São Paulo \\ Carolina Sanches Aranda \\ Universidade Federal de São Paulo \\ Allan Chiaratti de Oliveira \\ Universidade Federal de São Paulo \\ Thais das Neves Fraga Moreira \\ Universidade Federal de São Paulo \\ Lily Yin Weckx \\ Universidade Federal de São Paulo \\ Maria Isabel de Moraes-Pinto ( $\square$ m.isabelmp@uol.com.br) \\ Federal University of Sao Paulo https://orcid.org/0000-0001-7345-5477
}

\section{Research Article}

Keywords: BCG vaccine, vaccine adverse event, next-generation sequencing, primary immunodeficiency, inborn error of immunity

Posted Date: December 20th, 2021

DOI: https://doi.org/10.21203/rs.3.rs-1108372/v1

License: @ (i) This work is licensed under a Creative Commons Attribution 4.0 International License. Read Full License 


\section{Abstract}

Purpose: In Mycobacterium tuberculosis endemic regions, BCG vaccine is administered early after birth to confer protection against severe form of tuberculosis disease. Previous reports suggest that BCG adverse events, even localized ones (BCGitis), can be the first manifestation of immunodeficiency. We investigated children with a history of BCGitis who needed drug treatment looking for possibly pathogenic variants in inborn errors of immunity genes (IEIgenes).

Methods: Forty-four probands were evaluated. The exome sequences obtained by Next-Generation Sequencing were filtered for variants in the 344 IEl-genes described by the International Union of Immunological Societies (IUIS) and classified according to the recommendations of the American College of Medical Genetics. The identified candidate variants were validated by Sanger sequencing.

Results: Out of the 44 probands, 36 were sporadic cases and 8 were familial cases. Thirty-one in 44 (70.5\%) presented immunoallergic or other infectious clinical conditions besides BCGitis; 19 in 44 (43.2\%) presented variants classified as pathogenic or likely pathogenic in 17 different IEl-genes, of which $35.3 \%$ were genes related to defects in intrinsic and innate immunity, including Mendelian Susceptibility to Mycobacterial Disease (MSMD) genes (IRF8, IFNGR1, JAK1, STAT1, TLR3 and TBK1). Remaining genes were distributed in another five IUIS classifications groups (CARD14, CFH, CHD7, FOXN1, NFAT5, NLRP3, NOD2, PMS2, STAT3, TNFRSF13B and TNFSF12).

Conclusion: The high prevalence of pathogenic or likely pathogenic variants found in IEl-genes may be associated with BCGitis, which should be considered a sign of an inborn error of immunity.

\section{Introduction}

It is estimated that one quarter of individuals in the world are infected with Mycobacterium tuberculosis, but only 5-10\% become symptomatic [1]. A variety of factors are associated with development of tuberculosis disease, amongst which young age is included [2,3]. In M. tuberculosis endemic regions, BCG vaccine is administered early after birth and it is known to confer protection against severe forms of tuberculosis disease [4].

BCG is a live attenuated vaccine that can lead to adverse events (BCG-AE) which might be classified either as disseminated or localized [5]. Whereas disseminated BCG-AE (BCGosis) are indisputably associated with an underlying immunodeficiency [6-8], localized BCG-AE (BCGitis) are generally less severe and are often attributed to vaccine administration errors in Brazil [9].

Retrospective studies with patients diagnosed with Inborn Immunity Errors (IEI) - previously denominated as Primary Immunodeficiency Disease (PID) - have shown that localized BCG-AE also occurred in these patients $[6,10-13]$. However, the real frequency of individuals with IEI who develop localized BCG-AE as a first manifestation of the immunological impairment is unclear.

Whole exome sequencing (WES) has proven to be an effective tool to detect novel IEl-causing genes in patients with syndromes of unknown etiology [14, 15]. WES combined with selective analysis of IEl-associated genes has been effective in identifying 17 disease-causing variants in $30 \%$ of patients diagnosed with severe Common Variable Immunodeficiency (CVID) phenotypes [16]. The NGS WES analysis of 278 families with immunodeficiency from 22 countries focused on 475 IEl known or candidate genes and achieved a probable molecular diagnosis in 110 (40\%) unrelated patients [17].

Using a similar approach, we investigated patients with BCG localized adverse events and some close family members looking for pathogenic variants in genes known to cause IEls.

\section{Methods}

\section{Patient Selection}

This study performed a molecular assessment of children who presented with BCGitis after BCG vaccination. They were followed up at the Reference Center for Special Immunobiologicals and at the Immunology Clinic of the Department of Pediatrics at the Universidade Federal de São Paulo/UNIFESP, in São Paulo, Brazil, from 2009 to 2018. The Brazilian Ministry of Health criteria for BCGitis diagnosis were used in this study [9]. Children who had criteria indicating the use of a specific drug treatment (isoniazid - INH) and whose legal guardians accepted to participate in the study were included in the study and were named probands. For familial cases, when available, other affected family members were included. HIV infection was as exclusion criteria.

Patients were assessed for advanced immunological tests, such as flow cytometry immunophenotyping of $T$ cells (CD3+), CD4+ T cells (CD3+CD4+) and CD8+ T cells (CD3+CD8+), B cells (CD3-CD19+) and NK cells (CD3-CD56+CD16+). Phagocytic function assessment was performed using dihydrorhodamine test. Evaluation of the IFNY-IL-12/IL-23 axis defects was performed after specific stimulation of whole blood with BCG, BCG and IL-12p70 and BCG and IFNy, with subsequent dosage of IL-12p70 and IFNy in culture supernatant by the X-MAP technology [18]. Lymphocyte and monocyte expression of the IFNY receptor chain (CD119) ex vivo and of the IL-12 receptor chain b1 (CD212) after 72h stimulation with phytohemagglutinin were performed by flow cytometry. When necessary, complement assays were performed and serum immunoglobulins were assessed.

\section{Data Analysis}

Whole Exome Sequencing (WES) was performed on lon Torrent ${ }^{\mathrm{TM}}$ plataform according to manufactorer instructions (Supplemental methods).

Exome sequences determined by NGS of all cohort subjects were filtered for variants in the 344 genes associated with 354 Inborn Errors of Immunity (IEIGenes) described by the Primary Immunodeficiency Diseases Committee Report of International Union of Immunological Societies - IUIS [19]. Considering 
relationship between related genes to Mendelian Susceptibility to Mycobacterial Disease genes (MSMD-Genes) to BCGitis, three newly described genes in the IUIS update [20] were added to our analysis (Table S1). Further filtering steps were applied as specified on supplemental methods.

Candidate variants were validated by Sanger sequencing and then submitted to familial segregation.

To assess the importance of IEl-related genes on patients presenting with BCG adverse event, an enrichment analysis was performed using as control population WES data from 1,562 unrelated samples from the Baylor Hopkins Center for Mendelian Genomics, searching for rare single nucleotide variants (SNV) on IEl-related genes. A contingency table containing the number of individuals presenting these qualified SNVs was accomplished for each gene found in the BCG cohort samples and in the control samples. The $p$ value was determined by Fisher's exact test and it was subsequentially was corrected by Benjamini and Hochberg method.

For variant interpretation, the American College of Medical Genetics and the Association for Molecular Pathology (ACMG/AMP) guidelines [21] were used. Final classification was obtained using VarSome platform [22].

Probands who presented variants in IEl-Genes classified as Pathogenic or Likely Pathogenic were categorized according to clinical outcome in respect to the development of other symptoms besides BCGitis: Only BGCitis group, with probands who did not present other symptoms besides BCGitis; Mild or Transient Infectious Conditions group, with probands who presented mild or transient infectious conditions besides BCGitis; and Immunoallergic Conditions group, with probands with immunoallergic conditions besides BCGitis.

\section{Ethics}

This study was approved by the Ethics Committee of Universidade Federal de São Paulo (protocol number 842,006 and 1,641,734). All participants or legal guardians signed the consent forms.

\section{Results}

The 44 children (probands) with BCGitis from non-consanguineous Brazilian families included 36 probands without family history of other BCGitis (sporadic cases) and 8 probands with familial BCGitis (Figure 1, Table S2).

In four familial cases it was possible to analyze additional affected individuals (multiplex). In another four familial cases, only proband was analyzed (simplex). Among the probands simplex families, variants in IEI-Genes classified as Pathogenic or Likely Pathogenic were found in two probands (Family 7 and Family 13). Among the multiplex families, identified variants did not explain the family aggregation of BCGitis in three of them (Family 2 , Family 37 and Family 44) and these families will be subject to further analysis. The proband of Family 2 showed a variant in MSMD-Gene classified as Likely Pathogenic (Figure 1).

Among all probands, $70.5 \%$ (31/44) presented mild or transient infectious conditions or immunoallergic conditions besides BCGitis. Table 1 summarizes probands characteristics with Pathogenic or Likely Pathogenic variants by Group of clinical phenotypes.

Table 1 Characteristics of probands with Pathogenic and Likely Pathogenic variants by Group of clinical phenotypes of the probands

\begin{tabular}{|c|c|c|c|}
\hline Parameters & Only BCGitis & $\begin{array}{l}\text { BCGitis plus } \\
\text { Mild or Transient Infections }\end{array}$ & $\begin{array}{l}\text { BCGitis plus } \\
\text { Immunoallergic Conditions }\end{array}$ \\
\hline Number of probands & 6 & 3 & 10 \\
\hline Male (\%) & $3(50)$ & $3(100)$ & $6(60)$ \\
\hline Median age at BCGitis diagnosis in days (range) & $57(30-75)$ & $132(29-251)$ & $92(8-184)$ \\
\hline Median BCGitis treatment in days (range) & $142(0-181)$ & 178(150-249) & $96(32-212)$ \\
\hline Age at last clinical assessment in years (range) & $11(9-11)$ & $7(3-10)$ & $9(8-12)$ \\
\hline Leukopenia (\%) & $1(33)$ & 0 & $5(50)$ \\
\hline Persistent Limphopenia (\%) & 0 & 0 & $1(10)$ \\
\hline Alteration in IL12-IFNg axis (\%) & $3(50)$ & $1(33)$ & $8(80)$ \\
\hline Family history of Tuberculosis (\%) & 0 & 0 & $4(40)$ \\
\hline Hospitalization (\%) & 0 & $1(33)$ & $7(70)$ \\
\hline Number of Genes with variants P or LP & 6 & 3 & 11 \\
\hline Number of Variants $\mathrm{P}$ or LP & 6 & 4 & 14 \\
\hline
\end{tabular}


In the whole cohort, Pathogenic or Likely Pathogenic variants in IEl-Genes were found in 19/44 (43.2\%) of probands. Tables 2 to 4 shows Pathogenic or Likely Pathogenic variants in IEI-Genes, including parental origin of inherited alleles by groups of probands according to clinical phenotype.

Table 2

Relevant clinical, familial and laboratory characteristics of probands with clinical phenotype "Only BCGitis" with genetic variants classified as Pathogenic or

\begin{tabular}{|c|c|c|c|c|c|c|c|c|c|c|}
\hline Prob & BCG-AE & $\begin{array}{l}\text { Relevant } \\
\text { caracteristics }\end{array}$ & $\begin{array}{l}\text { Blood } \\
\text { cells }\end{array}$ & $\begin{array}{l}\text { IL12-IFNg } \\
\text { axis }\end{array}$ & GENE $^{\mathrm{a}}$ & Variant & $\begin{array}{l}\text { ClinVar/ } \\
\text { HGMD }\end{array}$ & $\begin{array}{l}\text { Genot/ } \\
\text { (inherit) }\end{array}$ & $\begin{array}{l}\text { Enrichment } \\
\text { analysis } \\
\text { (p value) }\end{array}$ & $\begin{array}{l}\begin{array}{l}\text { Variant } \\
\text { Classification } \\
\text { b }\end{array} \\
\text { (ACMG } \\
\text { Criteria)c }\end{array}$ \\
\hline 10_1 & $\begin{array}{l}\text { Injection site } \\
\text { abscess and } \\
\text { Suppurative } \\
\text { lymphadenitis }\end{array}$ & $\begin{array}{l}\text { Recurrent } \\
\text { lymphatic } \\
\text { edema in the } \\
\text { right arm } \\
\text { after BCG }\end{array}$ & normal & $\begin{array}{l}\text { Low IFNg } \\
\text { cytokine }\end{array}$ & $\mathrm{CFH}$ & $\begin{array}{l}\text { 1:196659285C>T } \\
\text { c.C1252T } \\
\text { p.P418S }\end{array}$ & $-/-$ & $\begin{array}{l}\text { het } \\
\text { (mother) }\end{array}$ & 0.02740 & $\begin{array}{l}\text { Likely } \\
\text { Pathogenic } \\
\text { (PS4, PM2, } \\
\text { PP2) }\end{array}$ \\
\hline 16_1 & $\begin{array}{l}\text { Regional } \\
\text { enlarged } \\
\text { lymph node > } \\
3 \mathrm{~cm}\end{array}$ & None & normal & normal & NFAT5 & $\begin{array}{l}\text { 16:69681120A>G } \\
\text { c.A161G } \\
\text { p.Q54R }\end{array}$ & $-1-$ & $\begin{array}{l}\text { het } \\
\text { (father) }\end{array}$ & 0.02740 & $\begin{array}{l}\text { Likely } \\
\text { Pathogenic } \\
\text { (PS4, PM2) }\end{array}$ \\
\hline 18_1 & $\begin{array}{l}\text { Suppurative } \\
\text { lymphadenitis }\end{array}$ & None & normal & $\begin{array}{l}\text { Low IFNg } \\
\text { and IL-12 } \\
\text { cytokines/ } \\
\text { absent } \\
\text { receptor } \\
\text { IFNg in } \\
\text { monocytes }\end{array}$ & $T L R 3$ & $\begin{array}{l}\text { 4:186998119G>A } \\
\text { c.G346A } \\
\text { p.D116N }\end{array}$ & $-1-$ & $\begin{array}{l}\text { het } \\
\text { (father) }\end{array}$ & 0.02740 & $\begin{array}{l}\text { Likely } \\
\text { Pathogenic } \\
\text { (PS4, PM2, } \\
\text { PP3) }\end{array}$ \\
\hline 29_1 & $\begin{array}{l}\text { Suppurative } \\
\text { lymphadenitis }\end{array}$ & $\begin{array}{l}\text { Exeresis of } \\
\text { lymph node } \\
\text { was required }\end{array}$ & normal & normal & TBK1 & $\begin{array}{l}12: 64873821 \mathrm{G}>\mathrm{T} \\
\text { c.G731T } \\
\text { p.G244V }\end{array}$ & $-/ D M$ & $\begin{array}{l}\text { het } \\
\text { (mother) }\end{array}$ & 0.02740 & $\begin{array}{l}\text { Pathogenic } \\
\text { (PS4, PM1, } \\
\text { PM2, PP2, } \\
\text { PP3) }\end{array}$ \\
\hline $2 \_1$ & $\begin{array}{l}\text { Regional } \\
\text { enlarged } \\
\text { lymph node > } \\
\text { 3cm }\end{array}$ & $\begin{array}{l}\text { Maternal } \\
\text { cousin had } \\
\text { BCGits }\end{array}$ & $\begin{array}{l}\text { transient } \\
\text { neutropenia }\end{array}$ & normal & STAT1 & $\begin{array}{l}\text { 2:191873713T>C } \\
\text { c.A255G } \\
\text { p. } 185 \mathrm{M}\end{array}$ & $-/-$ & $\begin{array}{l}\text { het } \\
\text { (father) }\end{array}$ & 0.02740 & $\begin{array}{l}\text { Likely } \\
\text { Pathogenic } \\
\text { (PS4, PM2, } \\
\text { PP2) }\end{array}$ \\
\hline 23_1 & $\begin{array}{l}\text { Suppurative } \\
\text { lymphadenitis }\end{array}$ & $\begin{array}{l}\text { Secondary } \\
\text { bacterial } \\
\text { infection } \\
\text { Sister had } \\
\text { BCGitis }\end{array}$ & normal & $\begin{array}{l}\text { Low IFNg } \\
\text { and IL-12 } \\
\text { cytokines }\end{array}$ & NOD2 & $\begin{array}{l}\text { 16:50733638G>A } \\
\text { c.G232A } \\
\text { p.A78T }\end{array}$ & $-/-$ & $\begin{array}{l}\text { het } \\
\text { (father) }\end{array}$ & 0.00073 & $\begin{array}{l}\text { Likely } \\
\text { Pathogenic } \\
\text { (PS4, PM2) }\end{array}$ \\
\hline
\end{tabular}

Prob. $=$ Proband $B C G-A E=$ Type of BCG adverse event $;(a)=$ Human Genome Reference GRCh37/hg19. VUS = Variant of Uncertain Significance: DM=disease-causing mutation; Genot./(inherit) = Genotype/(Inheritance); het = heterozygosis; comp-het = compound heterozygosis; IFN = Interferon; IL-12 = Interleukin-12; N/A = not available; HGMD = Human Gene Mutation Database; $(\dot{)})=$ using VarSome platform ; ACMG = American College of Medical Genetics; (c) Richards et al., 20 
Table 3

Relevant clinical, familial and laboratory characteristics of probands with clinical phenotype "Mild or Transient Infections" with genetic variants classified a Pathogenic or Likely Pathogenic

\begin{tabular}{|c|c|c|c|c|c|c|c|c|c|c|}
\hline Prob & BCG-AE & $\begin{array}{l}\text { Relevant } \\
\text { caracteristics }\end{array}$ & Blood cells & $\begin{array}{l}\text { IL12-IFNg } \\
\text { axis }\end{array}$ & GENE $^{a}$ & Variant & $\begin{array}{l}\text { ClinVar/ } \\
\text { HGMD }\end{array}$ & $\begin{array}{l}\text { Genot } \\
\text { (inherit) }\end{array}$ & $\begin{array}{l}\text { Enrichment } \\
\text { analysis } \\
\text { (p value) }\end{array}$ & $\begin{array}{l}\begin{array}{l}\text { Variant } \\
\text { Classifica' } \\
\text { b }\end{array} \\
\text { (ACMG } \\
\text { Criteria)c }\end{array}$ \\
\hline 3_1 & Ulcer $>1 \mathrm{~cm}$ & $\begin{array}{l}\text { Urinary tract } \\
\text { infection, } \\
\text { recurrent otitis }\end{array}$ & $\begin{array}{l}\text { transient } \\
\text { neutropenia }\end{array}$ & $\begin{array}{l}\text { Low IFNg } \\
\text { cytokine }\end{array}$ & TNFSF12 & $\begin{array}{l}\text { 17:7452627C>A } \\
\text { c.C157A } \\
\text { p.Q53K }\end{array}$ & $-1-$ & $\begin{array}{l}\text { het } \\
\text { (mother) }\end{array}$ & 0.02740 & $\begin{array}{l}\text { Likely } \\
\text { Pathogeni } \\
\text { (PS4, PP3 }\end{array}$ \\
\hline 57_1 & $\begin{array}{l}\text { Suppurative } \\
\text { Lymphadenitis }\end{array}$ & $\begin{array}{l}\text { Recurrent } \\
\text { pneumonia } \\
\text { with } \\
\text { hospitalization, } \\
\text { urinary tract } \\
\text { infection, } \\
\text { sinusitis, } \\
\text { normal CH100 } \\
\text { and C2; normal } \\
\text { Igs }\end{array}$ & N/A & N/A & $\mathrm{CFH}$ & $\begin{array}{l}\text { 1:196711052G }>C \\
\text { c.G3004C } \\
\text { p.G1002R }\end{array}$ & VUS / - & $\begin{array}{l}\text { het } \\
\text { (father) }\end{array}$ & 0.02740 & $\begin{array}{l}\text { Likely } \\
\text { Pathogeni } \\
\text { (PS4, PḾ } \\
\text { PP2) }\end{array}$ \\
\hline \multirow[t]{2}{*}{ 68_1 } & $\begin{array}{l}\text { Suppurative } \\
\text { Lymphadenitis }\end{array}$ & $\begin{array}{l}\text { BCGitis with } \\
\text { secondary } \\
\text { bacterial } \\
\text { infection with } \\
\text { hospitalization }\end{array}$ & $\begin{array}{l}\text { transient } \\
\text { low CD8 T } \\
\text { and NK } \\
\text { cells }\end{array}$ & $\begin{array}{l}\text { normal } \\
\text { receptors/ } \\
\text { cytokines } \\
\text { N/A }\end{array}$ & PMS2 & $\begin{array}{l}\text { 7:6035238G }>T \\
\text { c.C830A. } \\
\text { p.T277K }\end{array}$ & VUS / - & $\begin{array}{l}\text { comp- } \\
\text { het/ } \\
\text { (father) }\end{array}$ & 0.02740 & $\begin{array}{l}\text { VUS } \\
\text { (PS4, PME }\end{array}$ \\
\hline & & & & & PMS2 & $\begin{array}{l}\text { 7:6042238G>A } \\
\text { c.C383T } \\
\text { p.S128L }\end{array}$ & VUS / - & $\begin{array}{l}\text { comp- } \\
\text { het/ (no } \\
\text { mother - } \\
\text { no } \\
\text { father) }\end{array}$ & 0.02740 & $\begin{array}{l}\text { Pathogeni } \\
\text { (PS2, PS4 } \\
\text { PM2, PP3. }\end{array}$ \\
\hline
\end{tabular}

Prob. $=$ Proband; $B C G-A E=$ Type of BCG adverse event $\left({ }^{a}\right)=$ Human Genome Reference GRCh37/hg19. VUS = Variant of Uncertain Significance; $D M=$ diseasecausing mutation; Genot./(inherit) = Genotype/(Inheritance); het = heterozygosis; comp-het = compound heterozygosis; IFN = Interferon; IL-12 = Interleukin-12 $N / A=$ not available; HGMD = Human Gene Mutation Database; $\left({ }^{\dagger}\right)=$ using VarSome platform ; ACMG = American College of Medical Genetics; $(\mathcal{C})$ Richards et 2015. 
Table 4

Relevant clinical, familial and laboratory characteristics of probands with clinical phenotype "Immunoallergic conditions" with genetic variants classified as Pathogenic or Likely Pathogenic

\begin{tabular}{|c|c|c|c|c|c|c|c|c|c|c|}
\hline Prob & BCG-AE & $\begin{array}{l}\text { Relevant } \\
\text { caracteristics }\end{array}$ & $\begin{array}{l}\text { Blood } \\
\text { cells }\end{array}$ & $\begin{array}{l}\text { IL12- } \\
\text { IFNg axis }\end{array}$ & GENE $^{a}$ & Variant & $\begin{array}{l}\text { ClinVar/ } \\
\text { HGMD }\end{array}$ & $\begin{array}{l}\text { Genot/ } \\
\text { (inherit) }\end{array}$ & $\begin{array}{l}\text { Enrichment } \\
\text { analysis } \\
\text { ( } p \text { value) }\end{array}$ & $\begin{array}{l}\begin{array}{l}\text { Variant } \\
\text { Classification } \\
\text { b }\end{array} \\
\text { (ACMG }^{\text {Criteria) }}{ }^{\mathrm{c}}\end{array}$ \\
\hline 6_1 & $\begin{array}{l}\text { Suppurative } \\
\text { Lymphadenitis }\end{array}$ & $\begin{array}{l}\text { Asthma with } \\
\text { hospitalization; } \\
\text { recurrent } \\
\text { stomatitits }\end{array}$ & $\begin{array}{l}\text { transient } \\
\text { low B } \\
\text { cells }\end{array}$ & $\begin{array}{l}\text { Low IFNg } \\
\text { and IL-12 } \\
\text { cytokines }\end{array}$ & $C H D 7$ & $\begin{array}{l}\text { 8:61655415T }>C \\
\text { c. } 1424 \mathrm{C} \\
\text { p.M475T }\end{array}$ & $-/-$ & $\begin{array}{l}\text { het } \\
\text { (no } \\
\text { father, } \\
\text { no } \\
\text { mother) }\end{array}$ & 0.02740 & $\begin{array}{l}\text { Pathogenic } \\
\text { (PS2, PS4, } \\
\text { PM2, PP2) }\end{array}$ \\
\hline 11_1 & $\begin{array}{l}\text { Suppurative } \\
\text { Lymphadenitis }\end{array}$ & $\begin{array}{l}\text { Neonatal sepsis } \\
\text { and asseptic } \\
\text { meningitis, } \\
\text { recurrent } \\
\text { pneumonia with } \\
\text { hospitalization, } \\
\text { sinusitis, rinitis; } \\
\text { normal lgs, high } \\
\text { IgE (501Ul/mL). } \\
\text { Maternal uncle } \\
\text { and aunt had } \\
\text { TB }\end{array}$ & $\begin{array}{l}\text { low CD4 } \\
\text { T and } \\
\text { transient } \\
\text { low B } \\
\text { cells }\end{array}$ & $\begin{array}{l}\text { Low IFNg } \\
\text { cytokine }\end{array}$ & FOXN1 & $\begin{array}{l}\text { 17:26862145T>A } \\
\text { C.T1556A } \\
\text { p.L519Q }\end{array}$ & $\begin{array}{l}\text { VUS / } \\
\text { DM }\end{array}$ & $\begin{array}{l}\text { het } \\
\text { (father) }\end{array}$ & 0.02740 & $\begin{array}{l}\text { Likely } \\
\text { Pathogenic } \\
\text { (PS4, PM2, } \\
\text { PP3) }\end{array}$ \\
\hline \multirow[t]{2}{*}{ 14_1 } & \multirow[t]{2}{*}{$\begin{array}{l}\text { Injection site } \\
\text { abscess and } \\
\text { Suppurative } \\
\text { lymphadenitis }\end{array}$} & \multirow{2}{*}{$\begin{array}{l}\text { Asthma, } \\
\text { recurrent } \\
\text { pneumonia with } \\
\text { pleural effusion } \\
\text { and } \\
\text { hospitalization, } \\
\text { recurrent otitits, } \\
\text { atopic } \\
\text { dermatitits, } \\
\text { lactose and } \\
\text { gluten } \\
\text { intolerance; } \\
\text { elevated lgE } \\
(3.416 \mathrm{UI} / \mathrm{mL})\end{array}$} & normal & normal & $C H D 7$ & $\begin{array}{l}\text { 8:61764578G>A } \\
\text { C.G5666A } \\
\text { p.G1889D }\end{array}$ & $-/-$ & $\begin{array}{l}\text { het } \\
\text { (father) }\end{array}$ & 0.02740 & $\begin{array}{l}\text { Likely } \\
\text { Pathogenic } \\
\text { (PS4, PM2, } \\
\text { PP2) }\end{array}$ \\
\hline & & & & & STAT3 & $\begin{array}{l}\text { 17:40498688G>A } \\
\text { c.C172T P.H58Y }\end{array}$ & $-/ \mathrm{DM}$ & $\begin{array}{l}\text { het } \\
\text { (no } \\
\text { father, } \\
\text { no } \\
\text { mother) }\end{array}$ & 0.02740 & $\begin{array}{l}\text { Pathogenic } \\
\text { (PS2, PS4, } \\
\text { PM2, PP2, } \\
\text { PP3) }\end{array}$ \\
\hline 20_1 & $\begin{array}{l}\text { Suppurative } \\
\text { Lymphadenitis }\end{array}$ & $\begin{array}{l}\text { Asthma, } \\
\text { recurrent } \\
\text { pneumonia, } \\
\text { recurrent otitis. } \\
\text { Paternal great } \\
\text { uncle had TB } \\
\text { and paternal } \\
\text { cousins had } \\
\text { recurrent } \\
\text { pneumonia }\end{array}$ & normal & $\begin{array}{l}\text { Low IL- } \\
12 \\
\text { cytokine }\end{array}$ & NOD2 & $\begin{array}{l}16: 50744718 G>A \\
\text { c.G896A } \\
\text { p.G299D }\end{array}$ & $-1-$ & $\begin{array}{l}\text { het } \\
\text { (father) }\end{array}$ & 0.02740 & $\begin{array}{l}\text { Likely } \\
\text { Pathogenic } \\
\text { (PS4, PM1, } \\
\text { PM2, PP3) }\end{array}$ \\
\hline
\end{tabular}

Table 4 (continuation) - Relevant clinical, familial and laboratory characteristics of probands with clinical phenotype "Immunoallergic conditions" with genetic variants classified as Pathogenic or Likely Pathogenic 


\begin{tabular}{|c|c|c|c|c|c|c|c|c|c|c|}
\hline Prob & BCG-AE & $\begin{array}{l}\text { Relevant } \\
\text { caracteristics }\end{array}$ & $\begin{array}{l}\text { Blood } \\
\text { cells }\end{array}$ & $\begin{array}{l}\text { IL12- } \\
\text { IFNg axis }\end{array}$ & GENE $^{\mathrm{a}}$ & Variant & $\begin{array}{l}\text { ClinVar/ } \\
\text { HGMD }\end{array}$ & $\begin{array}{l}\text { Genot/ } \\
\text { (inherit) }\end{array}$ & $\begin{array}{l}\text { Enrichment } \\
\text { analysis } \\
\text { ( } p \text { value) }\end{array}$ & $\begin{array}{l}\text { Varial } \\
\text { Class } \\
\text { b } \\
\text { (ACN } \\
\text { Criteri }\end{array}$ \\
\hline \multirow[t]{5}{*}{ 21_1 } & $\begin{array}{l}\text { Suppurative } \\
\text { Lymphadenitis }\end{array}$ & \multirow{5}{*}{$\begin{array}{l}\text { Rhinitis. } \\
\text { Maternal } \\
\text { grandmother, } \\
\text { aunt and } \\
\text { cousin had TB }\end{array}$} & \multirow[t]{5}{*}{ normal } & \multirow[t]{5}{*}{ normal } & TNFRSF13B & $\begin{array}{l}\text { 17:16852187A>G } \\
\text { c.T310C }\end{array}$ & \multirow[t]{2}{*}{$\begin{array}{l}\text { VUS / } \\
\text { DM }\end{array}$} & \multirow{2}{*}{$\begin{array}{l}\text { het } \\
\text { (father) }\end{array}$} & \multirow[t]{2}{*}{0.42819} & \multirow{2}{*}{$\begin{array}{l}\text { Pathc } \\
\text { (PS1, } \\
\text { PM1, } \\
\text { PP2, } \\
\text { PP5) }\end{array}$} \\
\hline & & & & & & p.C104R & & & & \\
\hline & & & & & STAT1 & $\begin{array}{l}2: 191873774 \mathrm{~T}>\mathrm{C} \\
\text { c.A188G }\end{array}$ & $-1-$ & \multirow{2}{*}{$\begin{array}{l}\text { het } \\
\text { (father) }\end{array}$} & \multirow[t]{2}{*}{0.02740} & \multirow{2}{*}{$\begin{array}{l}\text { Likely } \\
\text { Pathe } \\
\text { (PS4, } \\
\text { PP2, I }\end{array}$} \\
\hline & & & & & & p.Q63R & & & & \\
\hline & & & & & $N L R P 3$ & $\begin{array}{l}\text { 1:247588562T>A } \\
\text { c. T1817A p.L606Q }\end{array}$ & $-1-$ & $\begin{array}{l}\text { het } \\
\text { (father) }\end{array}$ & 0.02740 & $\begin{array}{l}\text { Likely } \\
\text { Pathc } \\
\text { (PS4, } \\
\text { PP2) }\end{array}$ \\
\hline 27_1 & $\begin{array}{l}\text { Injection site } \\
\text { abscess }\end{array}$ & $\begin{array}{l}\text { Asthma, } \\
\text { recurrent } \\
\text { pneumonia } \\
\text { with } \\
\text { hospitalization. } \\
\text { Grandfather } \\
\text { had TB }\end{array}$ & normal & $\begin{array}{l}\text { Low IL- } \\
12 \\
\text { cytokine }\end{array}$ & IFNGR1 & $\begin{array}{l}6: 137527386 A>G \\
\text { c. } T 260 \mathrm{C} \\
\text { p. } 187 \mathrm{~T}\end{array}$ & $\begin{array}{l}\text { Pathogenic } \\
\text { /DM }\end{array}$ & $\begin{array}{l}\text { het } \\
\text { (father) }\end{array}$ & 0.02740 & $\begin{array}{l}\text { Pathc } \\
\text { (PS4, } \\
\text { PP3, I } \\
\text { PP5) }\end{array}$ \\
\hline 32_1 & $\begin{array}{l}\text { Suppurative } \\
\text { lymphadenitis } \\
\text { and secondary } \\
\text { bacterial } \\
\text { infection }\end{array}$ & $\begin{array}{l}\text { Asthma, } \\
\text { recurrent severe } \\
\text { pneumonia } \\
\text { with } \\
\text { hospitalizations }\end{array}$ & $\begin{array}{l}\text { transient } \\
\text { low NK } \\
\text { cells }\end{array}$ & $\begin{array}{l}\text { Low IL- } \\
12 \\
\text { cytokine }\end{array}$ & CHD7 & $\begin{array}{l}\text { 8:61654602G>T } \\
\text { c.G611T } \\
\text { p.G204V }\end{array}$ & $-/-$ & $\begin{array}{l}\text { het } \\
\text { (no } \\
\text { mother/ } \\
\text { (father } \\
\text { N/A) }\end{array}$ & 0.02740 & $\begin{array}{l}\text { Pathı } \\
\text { (PS4, } \\
\text { PM6, }\end{array}$ \\
\hline 50_1 & $\begin{array}{l}\text { Suppurative } \\
\text { Lymphadenitis }\end{array}$ & $\begin{array}{l}\text { Sepsis, asthma, } \\
\text { recurrent } \\
\text { pneumonia } \\
\text { with } \\
\text { hospitalization, } \\
\text { otitis and oral } \\
\text { moniliasis. } \\
\text { Brother had } \\
\text { recurrent } \\
\text { pneumonia }\end{array}$ & $\begin{array}{l}\text { transient } \\
\text { low total } \\
\text { CD 4 T, } \\
\text { naive } \\
\text { CD4 T } \\
\text { and B } \\
\text { cells }\end{array}$ & $\begin{array}{l}\text { Low IFNg } \\
\text { and IL-12 } \\
\text { cytokines }\end{array}$ & $J A K 1$ & $\begin{array}{l}\text { 1:65316585T>G } \\
\text { c.A1657C } \\
\text { p.N553H }\end{array}$ & $-1-$ & $\begin{array}{l}\text { het } \\
\text { (no } \\
\text { mother, } \\
\text { no } \\
\text { brother) }\end{array}$ & 0.02740 & $\begin{array}{l}\text { Likely } \\
\text { Pathc } \\
\text { (PS2, } \\
\text { PM2, }\end{array}$ \\
\hline
\end{tabular}

Table 4 (continuation) - Relevant clinical, familial and laboratory characteristics of probands with clinical phenotype "Immunoallergic conditions" with genetic variants classified as Pathogenic or Likely Pathogenic 


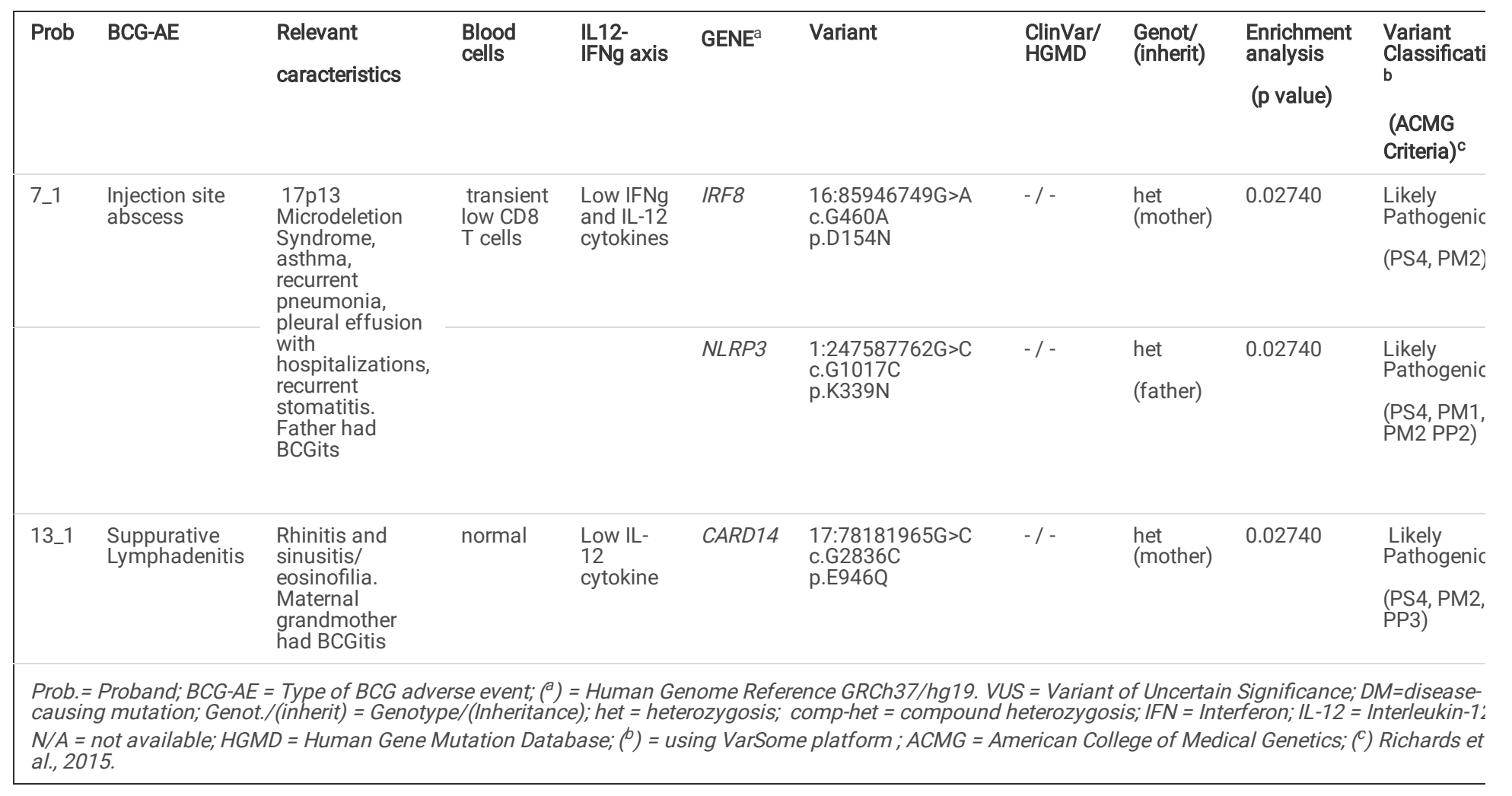

Six probands with Pathogenic or Likely Pathogenic variants in IEl-Genes presented clinical phenotype "Only BCGitis" (Table 2). Among them, four had suppurative lymphadenitis, one associated with injection site abscess and one associated with secondary bacterial infection. Two other probands had regional enlarged lymph node $>3 \mathrm{~cm}$. Fifty percent (3/6) presented altered IL12p70-IFNy axis: one with low IFNy, two with low IFNy and low IL-12 and one with low IFNY and IFNY receptor not detected. Six variants classified as Pathogenic or Likely Pathogenic in six different IEI-Genes were identified in WES of those six probands. Among these IEl-genes, 50\% (3/6) are related to defects in intrinsic and innate immunity (STAT1, TBK1 and TLR3). The remaining three genes are related to autoinflammatory disorders (NOD2), complement deficiencies (CFH) and immune deregulation diseases (NFAT5).

Three probands with Pathogenic or Likely Pathogenic variants in IEI-Genes presented clinical phenotype "Mild or Transient Symptoms" (Table 3). Two had suppurative lymphadenitis (SL) and one had an ulcer $>1 \mathrm{~cm}$ (UL). In this group, only $33.1 \%(1 / 3)$ of probands presented alteration in IL 12p70-IFNy axis (low IFNY) and 66.7\% (2/3) probands had transient cytopenia (one neutropenia and one low CD8 T and low NK cells). Three variants classified as Pathogenic or Likely Pathogenic in three different IEI-Genes were identified in WES of these three probands. One of these variants is compound heterozygosis. These genes are IEI-Gene related to combined immunodeficiencies with associated or syndromic features (PMS2), IEI-Gene related to predominantly antibody deficiencies (TNFSF12) and IEI-Gene related to complement deficiencies (CFH).

The largest clinical group of this cohort with detectable Pathogenic or Likely Pathogenic variants in IEl-Genes was composed of 10 probands with clinical phenotype "Immunoallergic conditions" (Table 4). Among them, eight had suppurative lymphadenitis (SL), one associated with injection site abscess (ISA) and another one, associated with secondary bacterial infection (BSI). Two other probands had injection site abscess (ISA). Seven out of $10(70 \%)$ required at least one hospital admission due to asthma or recurrent pneumonia and 8/10 (80\%) probands had an altered IL12p70-IFNy axis (seven with low IL-12, three with also low IFNy, and one with low IFNy). Cytopenia was identified in $6 / 10(60 \%)$ of these probands, of which $5 / 6(83.3 \%)$ were transient cytopenia (neutropenia, total lymphopenia, low CD4 T cells, low naive CD4 T cells, low B cells or low NK cells), and 1/6 (16.7\%) had persistent low CD4 T cells. Four out of 10 (40\%) probands reported tuberculosis cases in their families and another two probands were familial simplex cases of BCGitis.

WES identified 14 variants classified as Pathogenic or Likely Pathogenic in $11 \mathrm{IEl-Genes} \mathrm{in} \mathrm{these} 10$ probands. Three in 10 (30\%) had variants classified as Pathogenic or Likely Pathogenic in two or more genes each. Four of the 11 IEl-Genes $(36.4 \%)$ were related to defects in intrinsic and innate immunity (IFNGR1, IRF8, JAK1 and STAT1), all of them in MSMD-genes. Another 3/11(27.3\%) were IEl-genes related to autoinflammatory disorders (CARD14, NLRP12 and NOD2). Another 3/11 (27.3\%) were IEl-Genes related to combined immunodeficiencies with associated or syndromic features (CHD7, FOXN1, STAT3). One of the $11(9.0 \%)$ genes was an IEI-Genes related to predominantly antibody deficiencies (TNFRSF13B).

Figure 2 shows IEl-Genes variants classified as Pathogenic or Likely Pathogenic by group of clinical phenotypes of the probands, as well as the number of probands with variants in each IEI-Gene.

Parental origin of inherited alleles is also shown in Tables 2 to 4 . De novo variants classified as Pathogenic or Likely Pathogenic were found in 3 IEl-genes: CHD7, STAT3 and one allele of PMS2. One variant in JAK1 was also assumed to be de novo, as it was novel-LOF and it was not found in the WES of the mother and brother (father's sample unavailable for testing). Three other novel-LOF variants were found, two in CHD7 and one in STAT1.

All four novel-LOF variants classified as Pathogenic or Likely Pathogenic were found in probands with "Immunoallergic conditions" clinical phenotype. 


\section{Discussion}

Twenty-four Pathogenic or Likely Pathogenic variants were identified in $17 \mathrm{IEI}$-genes from $43.2 \%$ children of a Brazilian cohort of BCGitis. A significant percentage (70.5\%) of patients with BCGitis developed other clinical findings such as immunoallergic conditions or recurrent infections that required hospitalization and had altered immunological tests.

Timely diagnosis of IEl significantly improves the patient's outcome. However, as clinical phenotypes of IEl are very heterogeneous, a high level of suspicion is necessary for the diagnosis [23].

Many new IEls have been described recently. Although in constant expansion, the understanding of clinical phenotypes and the exact molecular mechanisms of all IEls are still limited [20]. Moreover, the percentage of IEls diagnoses based on BCGitis is still uncertain [24].

Severe BCG-AE are usually associated with genetic defects or allelic variants associated with IEl affecting innate or adaptive immunity [25]. Although BCGosis is more frequent in patients with severe clinical conditions such as severe combined immunodeficiency (SCID), localized BCG-AE have been described in these patients, with incidence rates ranging from $16.6 \%$ [12] to one third of patients investigated [26].

In this study, different in silico predictors and a search software, aggregator and impact analysis tool for human genetic variation - VarSome [22] - were used, in observance of ACMG criteria for variant pathogenicity classification.

As expected, there was a predominance of IEl-genes related to Defects in Intrinsic and Innate Immunity among variants classified as Pathogenic or Likely pathogenic: they represented 35.3\% (6/17) of IEl-genes with identified variants. Among them, the most frequent were MSMD-genes, with 4/17 (23.5\%) classified as Pathogenic or Likely Pathogenic variants.

MSMD is a group of rare innate immunity errors characterized by individual selective susceptibility to clinical disease caused by weakly virulent mycobacterial species, such as BCG strains and environmental mycobacteria, in healthy patients with normal resistance to other microorganisms, in the absence of immunological abnormalities evident in routine evaluation [27-29].

In countries where BCG is administered early in life, BCG infections are often the first sign of MSMD disease [28, 30, 31], with severity in patients with MSMD varying from localized infections to widespread and life-threatening infections [29, 32].

The incomplete penetrance in MSMD genes suggests the presence of modifying factors explaining different susceptibility of individuals with the same variant but with variable clinical outcomes [30]. Allelic heterogeneity can also interfere, as different defects of the same gene can result in different disorders [28, 33].

Among variants previously described in the literature and found in this study, one of them occurred in a MSMD-gene: a heterozygous variant in the IFNGR1 gene (Proband 27_1). This variant has been previously identified by Jouanguy et al. [34] as a partial IFNGR1 deficiency in one child with curable BCG infection and his sibling with latent tuberculosis. This variant was also reported by Remiszewski et al. [35] who identified a 20-year-old female with disseminated Mycobacterium avium disease involving bones, lungs and brain. She was completely healthy until this illness and had been vaccinated with BCG in infancy without complications. Functional analysis of this variant was performed by van de Wetering et al. [36] and confirmed that the severely reduced function of the $187 T$ mutant receptor can lead to partial IFNGR1 deficiency.

IFNGR1 deficiency caused by variants in IFNGR1 gene that are either autosomal recessive or autosomal dominant have a high degree of allelic, cellular and clinical phenotype heterogeneity [37-39]. Most recessive IFNGR1 deficiencies result in complete loss of cellular responsiveness to IFNy due to mutations that preclude the expression of IFNGR1 on the cell surface.

Another group of IFNGR1 deficiencies is due to missense mutations which result in normal expression of IFNGR1 at the cell surface, however, the resulting receptors show either diminished or hindered binding of IFNY [36]. This is compatible with the alterated IL12p70-IFNy axis test of proband 27_1.

Siblings reported by Jouanguy et al. [34] had also some degree of atopy, as observed with proband 27_1. Studies have shown that genetic variants in these IFN-pathway genes may have some degree of susceptibility to a range of common, chronic human diseases, which have an inflammatory component with high IgE levels and clinical phenotypes of asthma, atopic dermatitis and eczema herpeticum [40-42].

Variants associated to Autoinflammatory Disorders and classified as Pathogenic or Likely Pathogenic in IEl-Genes were found in 3/17 (17.6\%) of identified IEIgenes of this cohort. Interestingly, these variants were observed especially within probands from the group that displayed immunoallergic conditions.

In autoinflammatory disorders, IEl are usually caused by hyperfunction of the immune system, with frequent manifestations of recurrent inflammatory episodes [43]. Since the disease mechanism of various inflammatory disorders is related to increased production of proinflammatory cytokine IL1 $\beta$ and possible deviation from Th1 response to Th17, a less effective containment of BCG replication [44] could justify the BCG-AE presented by these patients.

No proband in the cohort presented a SCID phenotype and no variant classified as Pathogenic or Likely Pathogenic in IEI-Genes related to Immunodeficiencies affecting cellular and humoral immunity was identified. Although BCGitis is reported in SCID patients, BCG dissemination is more likely to occur [6].

Three variants classified as Pathogenic or Likely Pathogenic among IEl-genes related to Combined immunodeficiencies with associated or syndromic features were identified in $C H D 7$ gene. All patients had a phenotype of severe immunoallergic conditions with recurrent infections (Table 4). Two of the $C H D 7$ variants are novel (probands 14_1 and 32_1) and the other one is a de novo variant (proband 6_1).

Page 9/15 
Heterozygous pathogenic variants in $C H D 7$ are the most frequent cause of CHARGE Syndrome [45-47] and pathogenic $C H D 7$ variant is considered as a major criterion for the diagnosis of CHARGE syndrome (Hale et al., 2016). All three probands with variants in CHD7 will be investigated in depth and will be described in another article.

Proband 14_1 had another variant classified as pathogenic among IEl-genes related to Combined immunodeficiencies with associated or syndromic features: that was a de novo variant in STAT3. STAT3 acts as a central transcription factor downstream of multiple cytokine and growth factor receptors and thus regulates antimicrobial responses and cell survival [48]. STAT3 mutations can cause autosomal dominate hyper-lgE syndrome (AD-HIES), characterized by elevated IgE levels, persistent eczema, repeated skin abscesses, recurrent pneumonia with abscess and pneumatocele formation, candida infections, peculiar face and skeletal and connective tissue abnormalities $[49,50]$. This phenotype is compatible with the relevant clinical characteristics presented by proband 14_1, including high IgE levels.

Two of the 17 (11.8\%) Pathogenic or Likely Pathogenic variants were related to Predominantly Antibody Deficiencies IEI-genes (TNFSF12 and TNFRSF13B). Studies suggest antibodies can also provide protection against intracellular pathogens such as micobacteria by targeting innate immune antimicrobial activity via Fc receptor-mediated opsonization and phagocytosis [51-53], which are found in all innate immune cells [54]. Lu et al. [53] demonstrated that different antibody profiles appear to correlate with different stages of TB disease (active or latent) and may be able to lead to cell cytotoxicity mediated by NK cells, phagolysosomal maturation, inflammasome activation or intervene in other defense mechanisms.

The same can occur to humoral immune response to vaccination with BCG $[55,56]$. In this way, IEl that affect production of antibodies or B cell function may result in inefficiency to contain BCG replication, leading to an adverse event.

One proband from this cohort had a chromosome 17p13 Microdeletion Syndrome (proband 7_1). To date, no IEl-gene was identified in this region of chromosome 17 [57-60]. However, there are two reports associating of 17p13 microdeletion to thymic hypoplasia suggesting partial DiGeorge's Anomaly [61] and one case associated with T cell lymphopenia [62]. However, no monogenic disorder was identified in these two studies.

Among the family cases, many had relevant clinical conditions in addition to the BCG-AE, however, the genetic variants found did not meet the criteria adopted in this study for analysis, particularly an explanation for the familial aggregation of BCGitis.

Variants in IEl-genes classified as Pathogenic or Likely Pathogenic were found in all groups of clinical phenotypes analyzed (Figure 2). That is in line with the substantial phenotypic and clinical heterogeneity observed and described within groups of patients with variants in the same gene and even between individuals from same pedigree [63].

Diagnostic sequencing and genetic testing have the drawback that the effect of a variant on function cannot be inferred from sequencing alone, with a large proportion of variants classified as variants of uncertain significance (VUS) persisting in bioinformatic databases [64].

In this study, many cases with relevant clinical findings presented VUS variants or even no variants in IEI-Genes were found at all. Ewans et al. [65] observed that even if a disease-causing gene is not identified in a first analysis, or the variants found are initially classified as VUS, a future reanalysis increases molecular diagnoses. So, re-analyses will be carried out in due course and other groups of genes will be investigated in the probands of this cohort.

In this study we identified several cases in which the proband inherited a candidate causative variant from an unaffected parent. This observation led us to hypothesize a possible incomplete penetrance for those cases. Al Dhaheri et al. [66] raise four explanations for this sort of observation: a) a misclassification of a parent presenting a mild phenotype instead of being unaffected; b) an environmental effect requirement for this specific genotype; $c$ ) a bialelic variant requirement in which the second hit was lost due to technical limitation; and d) an oligogenic disease, in which the patient inherited the second failed gene from the other parent and, due to a technical limitation, it could not be identified.

Likewise, it is important to remember that the identification of associations between an allele and an observed clinical outcome does not necessarily mean that the allele itself conveys a functional difference [36].

The overall diagnostic yield of genetic variants identified by WES in cohorts of different pathologies varies in the literature from 5\% [67], 25,2\% [68] to 40 - 50\% $[69,70]$, even considering patients with immunological impairment $[16,17,71]$. From a genetic point of view, these yield variations can be explained, for example, by possible repeated expansion variants, somatic variants and deep intron variants with indeterminate splicing effects [70].

To identify which variants found in a WES might have functional or neutral changes remains challenging. Indeed, even using a standardized approach, a consensus classification is not achieved in $100 \%$ of cases even among experts [72]. This study does not intend to offer a definitive genetic diagnosis, but sought to demonstrate a possible relationship that a localized BCG-AE may indicate an IEl, emphasizing the importance of adequate follow-up and investigation of these patients.

To consider that children with localized BCG-AE may have some genetic-molecular disorder linked to an immunological defect is essential to define early intervention and prevent clinical complications and unfavorable outcome usually observed in children with undiagnosed primary immunodeficiencies timely.

As far as we know, this is the first study to assess exome of patients who had BCGitis using a panel of IEI-related genes, with many plausible variants identified, suggesting that BCGitis may be signaling an inborn error of immunity.

\section{Declarations}

\section{Funding}


- Fundação de Amparo à Pesquisa do Estado de São Paulo (FAPESP) (2014/27198-8)

- Conselho Nacional de Desenvolvimento Científico e Tecnológico (CNPq) (470671-2014-9)

- Baylor-Hopkins Center for Mendelian Genomics funded through National Human Genome Research Institute (grant 5U54HG006542) for providing control sample genomic data.

\section{Conflicts of interest/competing interests}

The authors declare no conflicts of Interest/competing interests

\section{Availability of data and material}

The raw data supporting the conclusions of this article can be made available by the authors under request.

\section{Code availability}

Not applicable

\section{Authors' contributions}

SAMGM, RPM and MIMP designed the study, performed data analysis and wrote the manuscript.

RFS, MMM, CPG, PV, ARM, PNA and EA performed data analysis and helped with manuscript preparation.

JBP, CSA and ACO discussed results and helped with manuscript preparation.

TNFM and LYW helped with collection of study samples and clinical information and with manuscript preparation.

All authors commented and approved the final version of the manuscript.

\section{Ethics approval}

This study was approved by the Ethics Committee of Universidade Federal de São Paulo $(842,006$ and $1,641,734)$.

\section{Consent to participate/ Consent for publication}

All participants or legal guardians signed the consent forms and provided consent for publication of data.

\section{Support Statement}

This study was funded by Fundação de Amparo à Pesquisa do Estado de São Paulo (FAPESP), Brazil: 2014/27198-8 and by Conselho Nacional de Desenvolvimento Científico e Tecnológico (CNPq), Brazil: 470671-2014-9

\section{Statement of interest}

none to declare

\section{References}

1. World Health Organization (WHO). Global Tuberculosis Report 2020. Available: https://apps.who.int/iris/bitstream/handle/10665/336069/9789240013131-eng.pdf

2. Marais BJ, Gie RP, Schaaf HS, Hesseling AC, Obihara CC, Nelson LJ, et al. The clinical epidemiology of childhood pulmonary tuberculosis: a critical review of literature from the pre-chemotherapy era. Int J Tuberc Lung Dis. 2004;8(3):278-85. [PubMed: 15139465]

3. Marais BJ, Gie RP, Schaaf HS, Hesseling AC, Obihara CC, Starke JJ, et al. The natural history of childhood intra-thoracic tuberculosis: a critical review of literature from the pre-chemotherapy era. Int J Tuberc Lung Dis. 2004;8(4):392-402. [PubMed: 15141729]

4. World Health Organization (WHO). BCG vaccine. Availabe: https://www.who.int/teams/health-product-and-policy-standards/standards-andspecifications/vaccines-quality/bcg

5. Smith KC, Orme IM, Starke JR. Tuberculosis vaccines. In: Plotkin S, Orenstein W, Offit P, editors. Vaccines. $7^{\text {th }}$ Edition. Philadelphia, PA:Elsevier, 2018. Pg1095-113.

6. Marciano BE, Huang CY, Joshi G, Rezaei N, Carvalho BC, Allwood Z, et al. BCG vaccination in patients with severe combined immunodeficiency: complications, risks, and vaccination policies. J Allergy Clin Immunol. 2014;133(4):1134-41. https://doi.org/10.1016/j.jaci.2014.02.028

7. Fischer A, Notarangelo LD, Neven B, Cavazzana M, Puck JM. Severe combined immunodeficiencies and related disorders. Nat Rev Dis Primers. 2015;1:15061. https://doi.org/10.1038/nrdp.2015.61

8. Bernatowska E, Skomska-Pawliszak M, Wolska-Kuśnierz B, Pac M, Heropolitanska-Pliszka E, Pietrucha B, et al. BCG Moreau Vaccine Safety Profile and NK Cells-Double Protection Against Disseminated BCG Infection in Retrospective Study of BCG Vaccination in 52 Polish Children with Severe Combined Immunodeficiency. J Clin Immunol. 2020;40(1):138-46. https://doi.org/10.1007/s10875-019-00709-1 
9. Ministério da Saúde (BR). Secretaria de Vigilância em Saúde. Departamento de Imunizações e Doenças Transmissíveis. Manual de Vigilância Epidemiológica de Eventos Adversos Pós-vacinação - 4. ed. - Brasília (DF); 2020. ISBN 978-85-334-2839-3. Available in

http://bvsms.saude.gov.br/bvs/publicacoes/manual_vigilancia_epidemiologica_eventos_vacinacao_4ed.pdf

10. Lee PP, Chan KW, Jiang L, Chen T, Li C, Lee TL, et al. Susceptibility to mycobacterial infections in children with X-linked chronic granulomatous disease: a review of 17 patients living in a region endemic for tuberculosis. Pediatr Infect Dis J. 2008;27(3):224-30. https://doi.org/10.1097/INF.0b013e31815b494c

11. Santos A, Dias A, Cordeiro A, Cordinhã C, Lemos S, Rocha G, et al. Severe axillary lymphadenitis after BCG vaccination: alert for primary immunodeficiencies. J Microbiol Immunol Infect. 2010;43(6):530-7. https://doi.org/10.1016/S1684-1182(10)60082-5

12. Mazzucchelli JT, Bonfim C, Castro GG, Condino-Neto AA, Costa NM, Cunha L, et al. Severe combined immunodeficiency in Brazil: management, prognosis, and BCG-associated complications. J Investig Allergol Clin Immunol. 2014;24(3):184-91. [PubMed: 25011356]

13. Sarmiento JD, Villada F, Orrego JC, Franco JL, Trujillo-Vargas CM. Adverse events following immunization in patients with primary immunodeficiencies. Vaccine. 2016;34(13):1611-6. https://doi.org/10.1016/j.vaccine.2016.01.047

14. Conley ME, Casanova JL. Discovery of single-gene inborn errors of immunity by next generation sequencing. Curr Opin Immunol. 2014;30:17-23. https://doi.org/10.1016/j.coi.2014.05.004

15. Retterer K, Juusola J, Cho MT, Vitazka P, Millan F, Gibellini F, et al. Clinical application of whole-exome sequencing across clinical indications. Genet Med. 2016;18(7):696-704. https://doi.org/10.1038/gim.2015.148

16. Maffucci P, Filion CA, Boisson B, Itan Y, Shang L, Casanova JL, et al. Genetic Diagnosis Using Whole Exome Sequencing in Common Variable Immunodeficiency. Front Immunol. 2016;7:220. https://doi.org/10.3389/fimmu.2016.00220

17. Stray-Pedersen A, Sorte HS, Samarakoon P, Gambin T, Chinn IK, Coban Akdemir ZH, et al. Primary immunodeficiency diseases: genomic approaches delineate heterogeneous Mendelian disorders. J Allergy Clin Immunol. 2017; 139(1):232-45. https://doi.org/10.1016/j.jaci.2016.05.042

18. Feinberg J, Fieschi C, Doffinger R, Feinberg M, Leclerc T, Boisson-Dupuis S, et al. Bacillus Calmette Guerin triggers the IL-12/IFN-gamma axis by an IRAK-4and NEMO-dependent, non-cognate interaction between monocytes, NK, and T lymphocytes. Eur J Immunol. 2004;34(11):3276-84. https://doi.org/10.1002/eji.200425221

19. Picard C, Bobby Gaspar H, Al-Herz W, Bousfiha A, Casanova J-L, Chatila T, et al. International Union of Immunological Societies: 2017 primary immunodeficiency diseases committee report on inborn errors of immunity. J Clin Immunol. 2018; 38(1):96-128. https://doi.org/10.1007/s10875-0170464-9

20. Tangye SG, Al-Herz W, Bousfiha A, Chatila T, Cunningham-Rundles C, Etzioni A, et al. Human inborn errors of immunity: 2019 update on the classification from the International Union of Immunological Societies Expert Committee. J Clin Immunol. 2020; 40(1):24-64, https://doi.org/10.1007/s10875-01900737-x

21. Richards S, Aziz N, Bale S, Bick D, Das S, Gastier-Foster J, et al. Standards and guidelines for the interpretation of sequence variants: a joint consensus recommendation of the American College of Medical Genetics and Genomics and the Association for Molecular Pathology. Genet Med. 2015; 17(5):40524. https://doi.org/10.1038/gim.2015.30

22. Kopanos C, Tsiolkas V, Kouris A, Chapple CE, Albarca Aguilera M, Meyer R, et al. VarSome: the human genomic variant search engine. Bioinformatics. 2019;35(11):1978-80. https://doi.org/10.1093/bioinformatics/bty897

23. Shields AM, Patel SY. The primary immunodeficiency disorders. Medicine. 2017;45(10),597-604. https://doi.org/10.1016/j.mpmed.2017.07.011

24. Bucciol G, Moens L, Bosch B, Bossuyt X, Casanova JL, Puel A, et al. Lessons learned from the study of human inborn errors of innate immunity. J Allergy Clin Immunol. 2019;143(2):507-527. https://doi.org/10.1016/j.jaci.2018.07.013

25. Norouzi S, Aghamohammadi A, Mamishi S, Rosenzweig SD, Rezaei N. Bacillus Calmette-Guérin (BCG) complications associated with primary immunodeficiency diseases. J Infect. 2012;64(6):543-54. https://doi.org/10.1016/j.jinf.2012.03.012

26. Nunes-Santos CJ, Rosenzweig SD. Bacille Calmette-Guerin Complications in Newly Described Primary Immunodeficiency Diseases: 2010-2017. Front Immunol. 2018;9:1423. https://doi.org/10.3389/fimmu.2018.01423

27. Casanova JL. Severe infectious diseases of childhood as monogenic inborn errors of immunity. Proc Natl Acad Sci U S A. 2015;112(51):E7128-37. https://doi.org/10.1073/pnas.1521651112

28. Pöyhönen L, Bustamante J, Casanova JL, Jouanguy E, Zhang Q. Life-Threatening Infections Due to Live-Attenuated Vaccines: Early Manifestations of Inborn Errors of Immunity. J Clin Immunol. 2019;39(4):376-90. https://doi.org/10.1007/s10875-019-00642-3

29. Bustamante J. Mendelian susceptibility to mycobacterial disease: recent discoveries. Hum Genet. 2020;139(6-7):993-1000. https://doi.org/10.1007/s00439-020-02120-y

30. Bustamante J, Boisson-Dupuis S, Abel L, Casanova J-L. Mendelian susceptibility to mycobacterial disease: genetic, immunological, and clinical features of inborn errors of IFN- $y$ immunity. Semin Immunol. 2014; 26(6):454-70. https://doi.org/10.1016/j.smim.2014.09.008

31. Reed B, Dolen WK. The Child with Recurrent Mycobacterial Disease. Curr Allergy Asthma Rep. 2018;18(8):44. https://doi.org/10.1007/s11882-018-0797-3

32. Rosain J, Kong XF, Martinez-Barricarte R, Oleaga-Quintas C, Ramirez-Alejo N, Markle J, et al. Mendelian susceptibility to mycobacterial disease: $2014-2018$ update. Immunol Cell Biol. 2019;97(4):360-7. https://doi.org/10.1111/imcb.12210

33. Casanova JL, Abel L. Human genetics of infectious diseases: Unique insights into immunological redundancy. Semin Immunol. 2018;36:1-12. https://doi.org/10.1016/j.smim.2017.12.008

34. Jouanguy E, Lamhamedi-Cherradi S, Altare F, Fondanèche MC, Tuerlinckx D, Blanche S, et al. Partial interferon-gamma receptor 1 deficiency in a child with tuberculoid bacillus Calmette-Guérin infection and a sibling with clinical tuberculosis. J Clin Invest. 1997;100(11):2658-64.

https://doi.org/10.1172/JCl119810

Page $12 / 15$ 
35. Remiszewski P, Roszkowska-Sliz B, Winek J, Chapgier A, Feinberg J, Langfort R, et al. Disseminated Mycobacterium avium infection in a 20-year-old female with partial recessive IFNgammaR1 deficiency. Respiration. 2006;73(3):375-8. https://doi.org/10.1159/000088682

36. van de Wetering D, de Paus RA, van Dissel JT, van de Vosse E. Functional analysis of naturally occurring amino acid substitutions in human IFNgammaR1. Mol Immunol. 2010;47(5):1023-30. https://doi.org/10.1016/j.molimm.2009.11.016

37. Dorman SE, Picard C, Lammas D, Heyne K, van Dissel JT, Baretto R, et al. Clinical features of dominant and recessive interferon gamma receptor 1 deficiencies. Lancet. 2004;364(9451):2113-21. https://doi.org/10.1016/S0140-6736(04)17552-1

38. van de Vosse E, van Dissel JT. IFN-yR1 defects: Mutation update and description of the IFNGR1 variation database. Hum Mutat. 2017;38(10):1286-96. https://doi.org/10.1002/humu.23302

39. Glanzmann B, Möller M, Moncada-Velez M, Peter J, Urban M, van Helden PD, et al. Autosomal Dominant IFN-yR1 Deficiency Presenting with both Atypical Mycobacteriosis and Tuberculosis in a BCG-Vaccinated South African Patient. J Clin Immunol. 2018;38(4):460-3. https://doi.org/10.1007/s10875-0180509-8

40. Gao L, Bin L, Rafaels NM, Huang L, Potee J, Ruczinski I, Beaty TH, et al. Targeted deep sequencing identifies rare loss-of-function variants in IFNGR1 for risk of atopic dermatitis complicated by eczema herpeticum. J Allergy Clin Immunol. 2015;136(6):1591-1600. https://doi.org/10.1016/j.jaci.2015.06.047

41. Leung DY, Gao PS, Grigoryev DN, Rafaels NM, Streib JE, Howell MD, et al. Human atopic dermatitis complicated by eczema herpeticum is associated with abnormalities in IFN-y response. J Allergy Clin Immunol. 2011;127(4):965-73e1-5. https://doi.org/10.1016/j.jaci.2011.02.010

42. Gao PS, Mao XQ, Jouanguy E, Pallier A, Döffinger R, Tanaka Y, et al. Nonpathogenic common variants of IFNGR1 and IFNGR2 in association with total serum IgE levels. Biochem Biophys Res Commun. 1999;263(2):425-9. https://doi.org/10.1006/bbrc.1999.1368

43. Oda H, Kastner DL. Genomics, Biology, and Human Illness: Advances in the Monogenic Autoinflammatory Diseases. Rheum Dis Clin North Am. 2017;43(3):327-45. https://doi.org/10.1016/j.rdc.2017.04.011

44. Smith SG, Zelmer A, Blitz R, Fletcher HA, Dockrell HM. Polyfunctional CD4 T-cells correlate with in vitro mycobacterial growth inhibition following Mycobacterium bovis BCG-vaccination of infants. Vaccine. 2016;34(44):5298-305. https://doi.org/10.1016/j.vaccine.2016.09.002

45. Bergman JE, Janssen N, Hoefsloot LH, Jongmans MC, Hofstra RM, van Ravenswaaij-Arts CM. CHD7 mutations and CHARGE syndrome: the clinical implications of an expanding phenotype. J Med Genet. 2011;48(5):334-42. https://doi.org/10.1136/jmg.2010.087106

46. Bergman JE, Janssen N, van der Sloot AM, de Walle HE, Schoots J, Rendtorff ND, et al. A novel classification system to predict the pathogenic effects of CHD7 missense variants in CHARGE syndrome. Hum Mutat. 2012;33(8):1251-60. https://doi.org/10.1002/humu.22106

47. Janssen N, Bergman JE, Swertz MA, Tranebjaerg L, Lodahl M, Schoots J, et al. Mutation update on the CHD7 gene involved in CHARGE syndrome. Hum Mutat. 2012;33(8):1149-60. https://doi.org/10.1002/humu.22086

48. Mogensen TH. STAT3 and the Hyper-lgE syndrome: Clinical presentation, genetic origin, pathogenesis, novel findings and remaining uncertainties. JAKSTAT. 2013;2(2):e23435. https://doi.org/10.4161/jkst.23435

49. Kandilarova SM, Lesichkova SS, Gesheva NT, Yankova PS, Ivanov NH, Stoyanova GP, et al. On Two Cases with Autosomal Dominant Hyper IgE Syndrome: Importance of Immunological Parameters for Clinical Course and Follow-Up. Case Reports Immunol. 2020;2020:6694957.

https://doi.org/10.1155/2020/6694957

50. Xiang Q, Zhang L, Liu X, Wang S, Wang T, Xiao M, et al. Autosomal dominant hyper lgE syndrome from a single centre in Chongqing, China (2009-2018). Scand J Immunol. 2020;91(6):e12885. https://doi.org/10.1111/sji.12885

51. Jacobs AJ, Mongkolsapaya J, Screaton GR, McShane H, Wilkinson RJ. Antibodies and tuberculosis. Tuberculosis (Edinb). 2016;101:102-13. https://doi.org/10.1016/j.tube.2016.08.001

52. Achkar JM, Chan J, Casadevall A. B cells and antibodies in the defense against Mycobacterium tuberculosis infection. Immunol Rev. 2015;264(1):167-81. https://doi.org/10.1111/imr.12276

53. Lu LL, Chung AW, Rosebrock TR, Ghebremichael M, Yu WH, Grace PS, et al. A Functional Role for Antibodies in Tuberculosis. Cell. 2016;167(2):433-43e14. https://doi.org/10.1016/j.cell.2016.08.072

54. Casadevall A, Pirofski LA. A reappraisal of humoral immunity based on mechanisms of antibody-mediated protection against intracellular pathogens. Adv Immunol. 2006;91:1-44. https://doi.org/10.1016/S0065-2776(06)91001-3

55. Tanner R, Villarreal-Ramos B, Vordermeier HM, McShane H. The Humoral Immune Response to BCG Vaccination. Front Immunol. 2019;10:1317. https://doi.org/10.3389/fimmu.2019.01317

56. Krocova Z, Plzakova L, Pavkova I, Kubelkova K, Macela A, Ozanic M, et al. The role of B cells in an early immune response to Mycobacterium bovis. Microb Pathog. 2020;140:103937. https://doi.org/10.1016/j.micpath.2019.103937

57. Barros Fontes MI, Dos Santos AP, Rossi Torres F, Lopes-Cendes I, Cendes F, Appenzeller S, et al. 17p13.3 Microdeletion: Insights on Genotype-Phenotype Correlation. Mol Syndromol. 2017;8(1):36-41. https://doi.org/10.1159/000452753

58. Blazejewski SM, Bennison SA, Smith TH, Toyo-Oka K. Neurodevelopmental Genetic Diseases Associated with Microdeletions and Microduplications of Chromosome 17p13.3. Front Genet. 2018;9:80. https://doi.org/10.3389/fgene.2018.00080

59. Emrick LT, Rosenfeld JA, Lalani SR, Jain M, Desai NK, Larson A, et al. Microdeletions excluding YWHAE and PAFAH1B1 cause a unique leukoencephalopathy: further delineation of the 17p13.3 microdeletion spectrum. Genet Med. 2019;21(7):1652-56. https://doi.org/10.1038/s41436-0180358-0

60. Romano C, Ferranti S, Mencarelli MA, Longo I, Renieri A, Grosso S. 17p13.3 microdeletion including YWHAE and CRK genes: towards a clinical characterization. Neurol Sci. 2020;41(8):2259-62. https://doi.org/10.1007/s10072-020-04424-3 
61. Greenberg F, Courtney KB, Wessels RA, Huhta J, Carpenter RJ, Rich DC, et al. Prenatal diagnosis of deletion 17p13 associated with DiGeorge anomaly. Am J Med Genet. 1988;31(1):1-4. https://doi.org/10.1002/ajmg.1320310102

62. Chee SY, Guo JW, Huang CJ, Chien YH, Lee YC, Feng WK. Rare Concurrence of Two Congenital Disorders: Miller-Dieker Syndrome and T-Cell Lymphopenia. Cytogenet Genome Res. 2019;157(4):227-30. https://doi.org/10.1159/000499956

63. Casanova JL, Conley ME, Seligman SJ, Abel L, Notarangelo LD. Guidelines for genetic studies in single patients: lessons from primary immunodeficiencies. J Exp Med. 2014;211(11):2137-49. https://doi.org/10.1084/jem.20140520

64. Almarzooqi F, Souid AK, Vijayan R, Al-Hammadi S. Novel genetic variants of inborn errors of immunity. PLoS One. 2021;16(1):e0245888. https://doi.org/10.1371/journal.pone.0245888

65. Ewans LJ, Schofield D, Shrestha R, Zhu Y, Gayevskiy V, Ying K, et al. Whole-exome sequencing reanalysis at 12 months boosts diagnosis and is costeffective when applied early in Mendelian disorders. Genet Med. 2018;20(12):1564-74. https://doi.org/10.1038/gim.2018.39

66. Al Dhaheri N, Wu N, Zhao S, Wu Z, Blank RD, Zhang J, et al. KIAA1217: A novel candidate gene associated with isolated and syndromic vertebral malformations. Am J Med Genet A. 2020;182(7):1664-72. https://doi.org/10.1002/ajmg.a.61607

67. Feltran LS, Varela P, Silva ED, Veronez CL, Franco MC, Filho AP, et al. Targeted Next-Generation Sequencing in Brazilian Children with Nephrotic Syndrome Submitted to Renal Transplant. Transplantation. 2017;101(12):2905-12. https://doi.org/10.1097/TP.0000000000001846

68. Yang Y, Muzny DM, Xia F, Niu Z, Person R, Ding Y, et al. Molecular findings among patients referred for clinical whole-exome sequencing. JAMA. 2014;312(18):1870-9. https://doi.org/10.1001/jama.2014.14601

69. Wright CF, McRae JF, Clayton S, Gallone G, Aitken S, FitzGerald TW, et al. Making new genetic diagnoses with old data: iterative reanalysis and reporting from genome-wide data in 1,133 families with developmental disorders. Genet Med. 2018;20(10):1216-23. https://doi.org/10.1038/gim.2017.246

70. Ki CS. Recent Advances in the Clinical Application of Next-Generation Sequencing. Pediatr Gastroenterol Hepatol Nutr. 2021;24(1):1-6. https://doi.org/10.5223/pghn.2021.24.1.1

71. Cifaldi C, Brigida I, Barzaghi F, Zoccolillo M, Ferradini V, Petricone D, et al. Targeted NGS Platforms for Genetic Screening and Gene Discovery in Primary Immunodeficiencies. Front Immunol. 2019;10:316. https://doi.org/10.3389/fimmu.2019.00316

72. Amendola LM, Jarvik GP, Leo MC, McLaughlin HM, Akkari Y, Amaral MD, et al. Performance of ACMG-AMP Variant-Interpretation Guidelines among Nine Laboratories in the Clinical Sequencing Exploratory Research Consortium. Am J Hum Genet. 2016;98(6):1067-76.

https://doi.org/10.1016/j.ajhg.2016.03.024

\section{Figures}

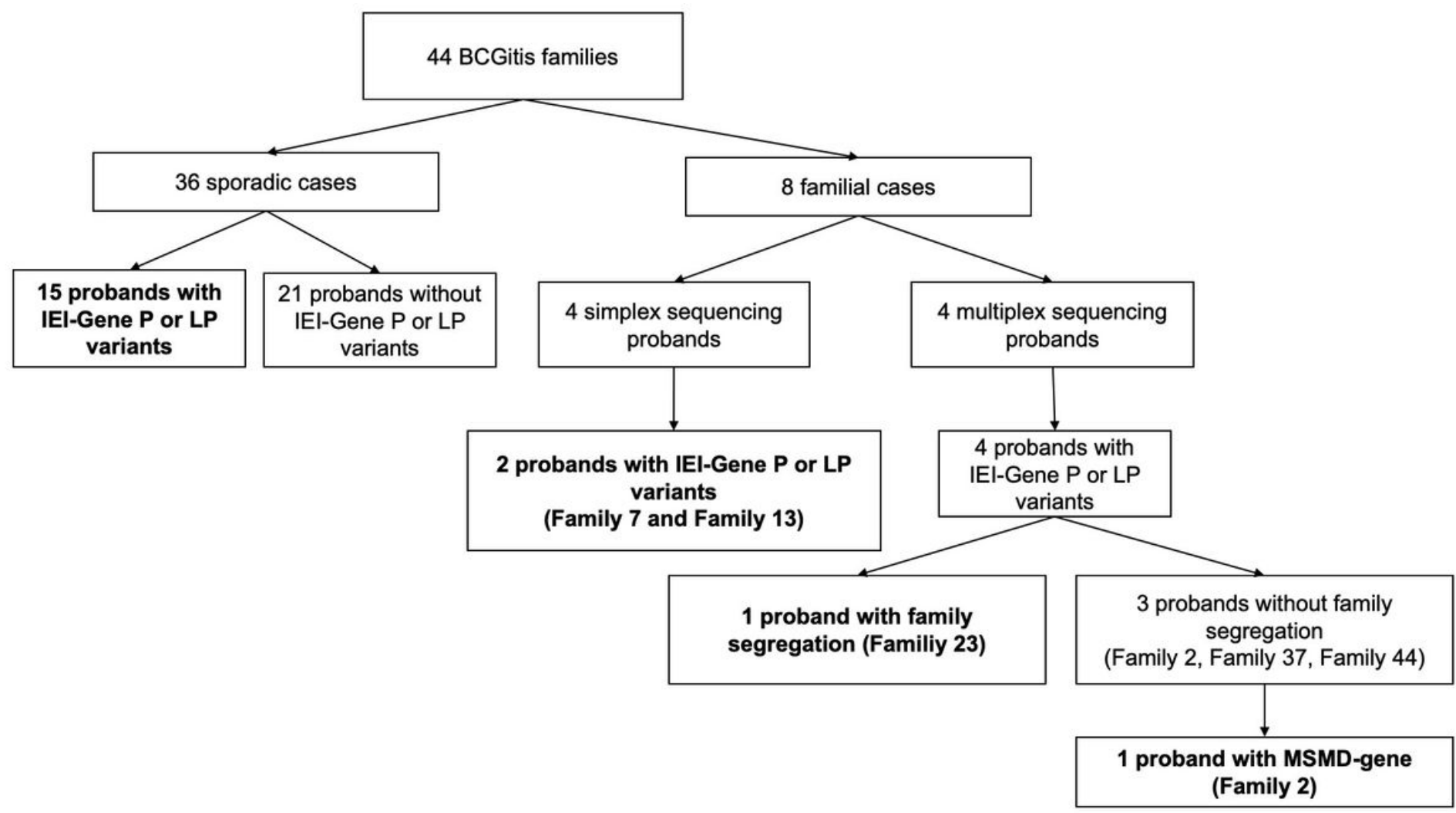

Figure 1

Description of study cohort. IEl-Genes: Genes related to Inborn Errors of Immunity. P: Pathogenic variant. LP: Likely Pathogenic variant. MSMD-Gene: Genes related to Mendelian susceptibility to mycobacterial diseases. 


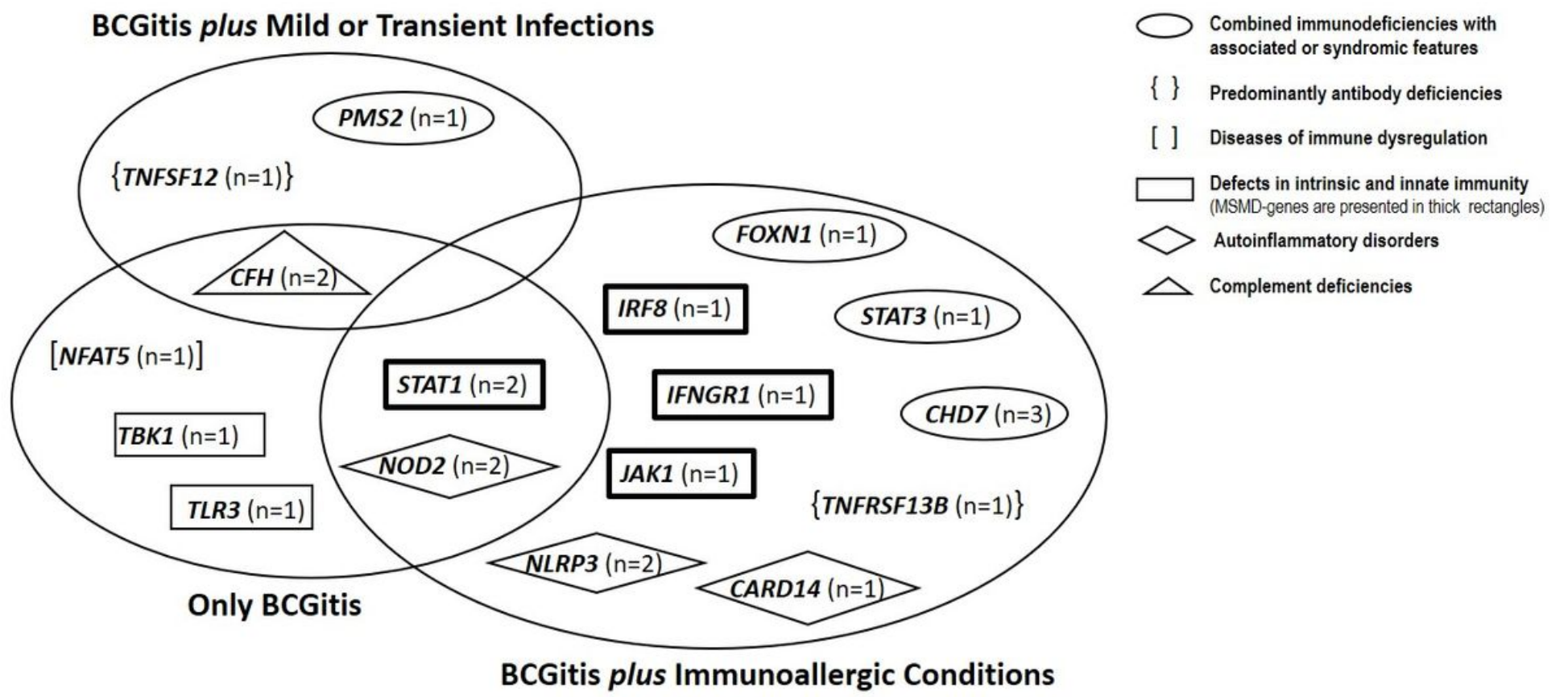

Figure 2

Genes related to Inborn Errors of Immunity in which variants classified as Pathogenic or Likely Pathogenic were identified, by Group of clinical phenotypes of the probands. Number of probands with variants in each gene is shown in parentheses. IEl-genes Classification according IUIS 2020 (Tangye et al., 2020 ).

\section{Supplementary Files}

This is a list of supplementary files associated with this preprint. Click to download.

- SupplemTable1.docx

- SupplemTable2.docx 